\title{
Simple and Efficient Solution Phase Synthesis of Oligonucleotides using Extractive Work-Up
}

Martijn C. de Koning, Amar B.T. Ghisaidoobe, Howard I. Duynstee, Paul B.W. Ten

Kortenaar, Dmitri V. Filippov and Gijs A. van der Marel

Leiden Institute of Chemistry, Gorlaeus Laboratories, P.O.Box 9502, 2300 RA, Leiden, The Netherlands, and Diosynth B.V., P.O.Box 20, 5340 BH, Oss, The Netherlands

SUPPORTING INFORMATION

SPECTRA 


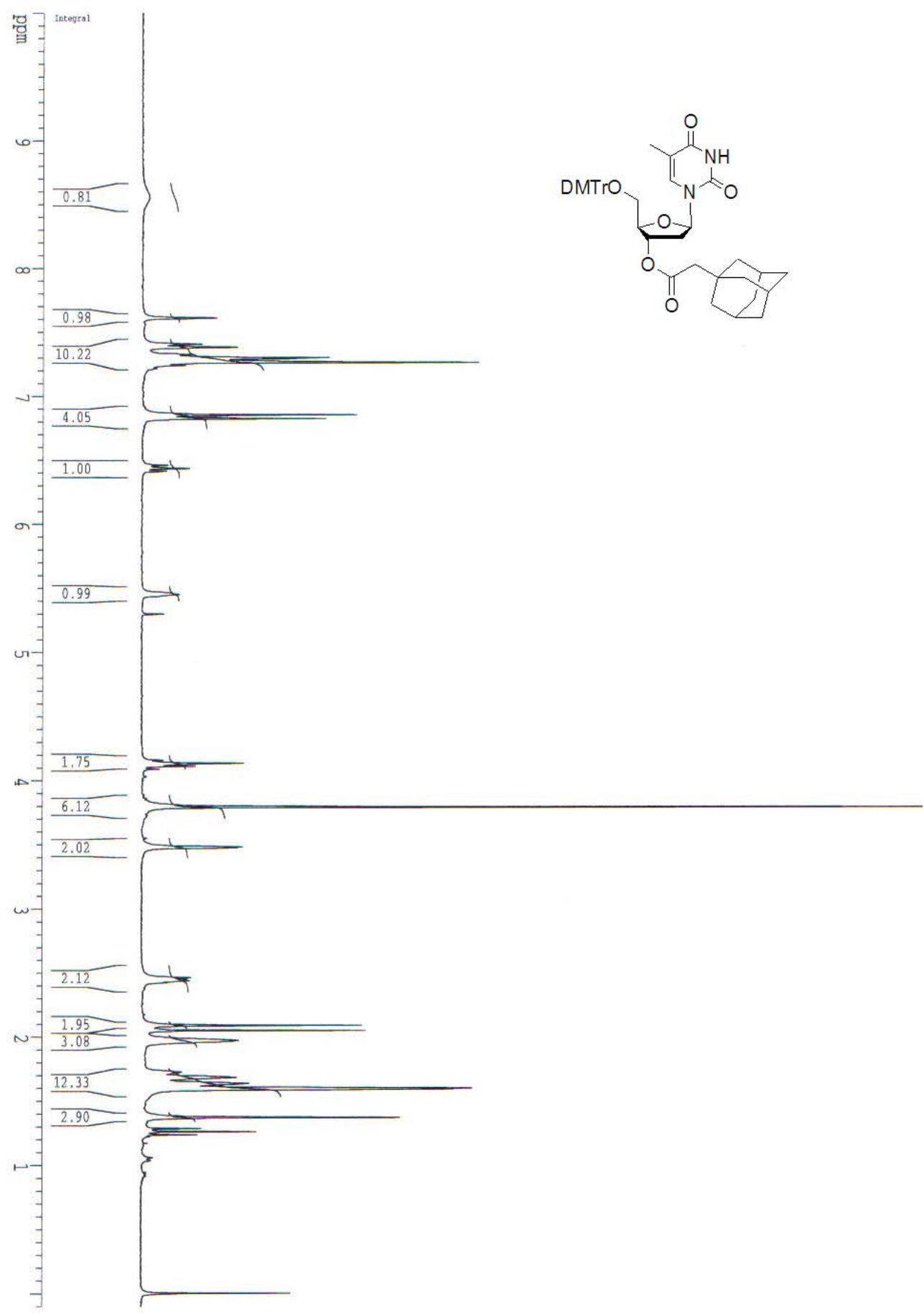




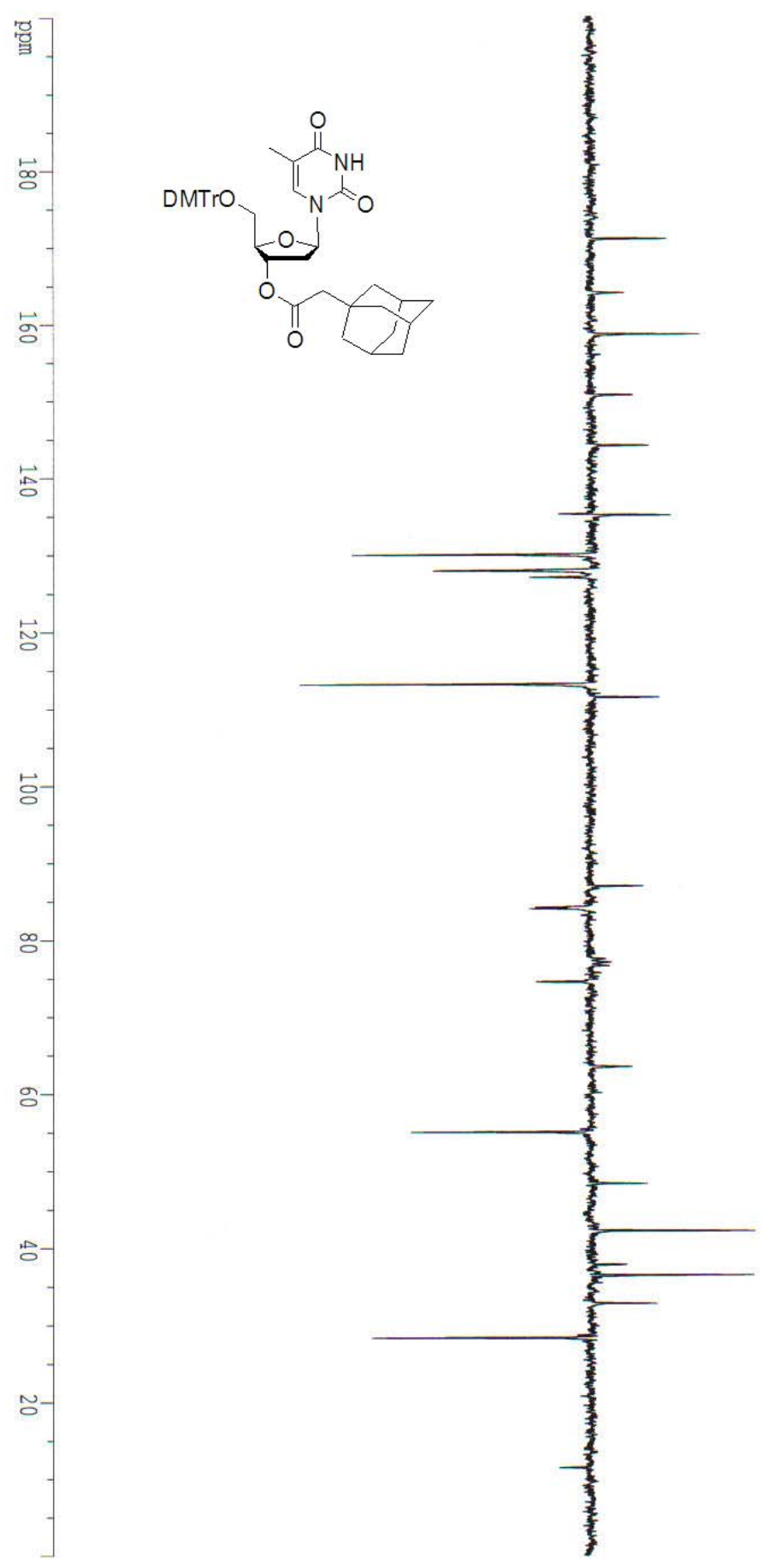




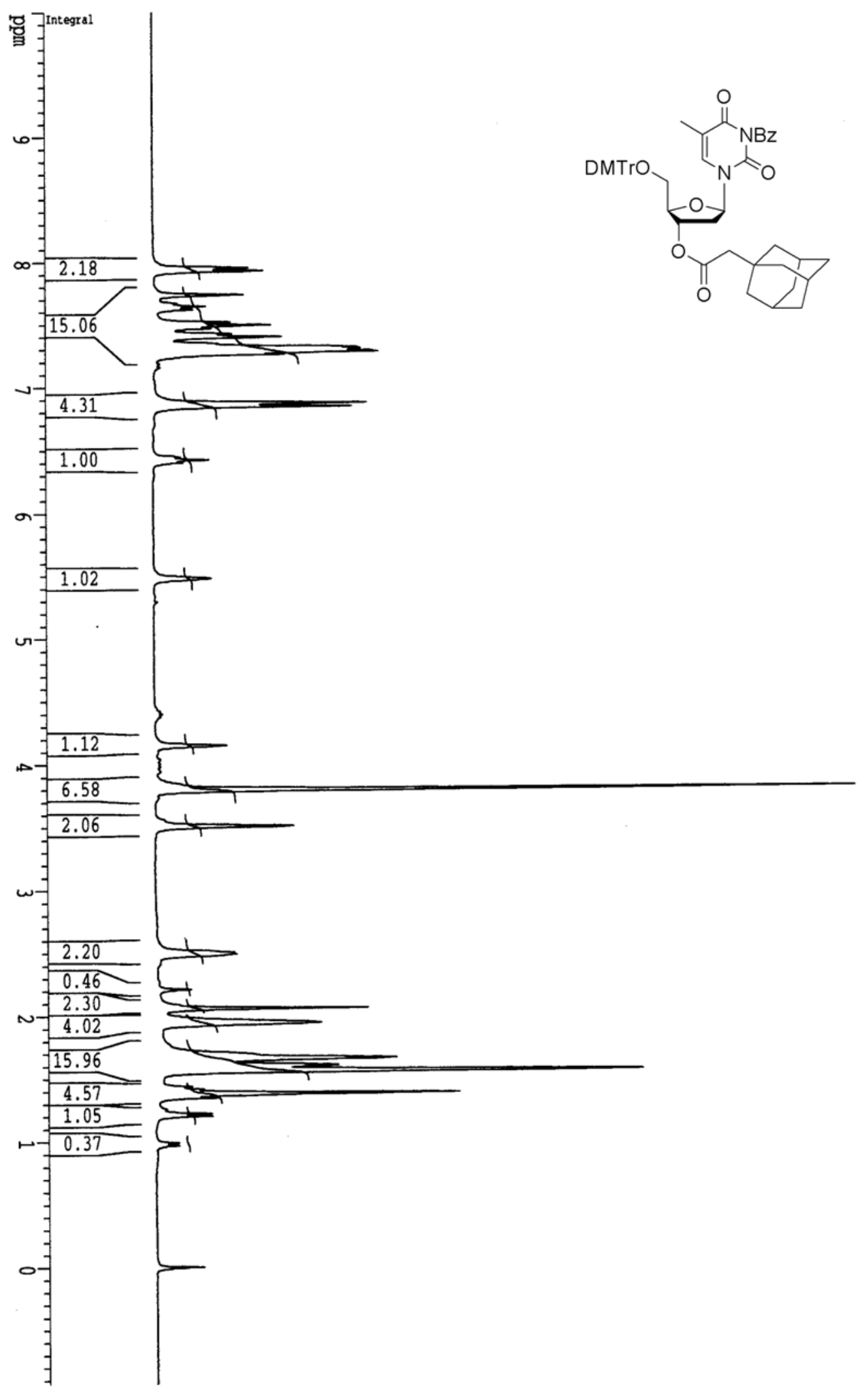




$$
1 \mid
$$




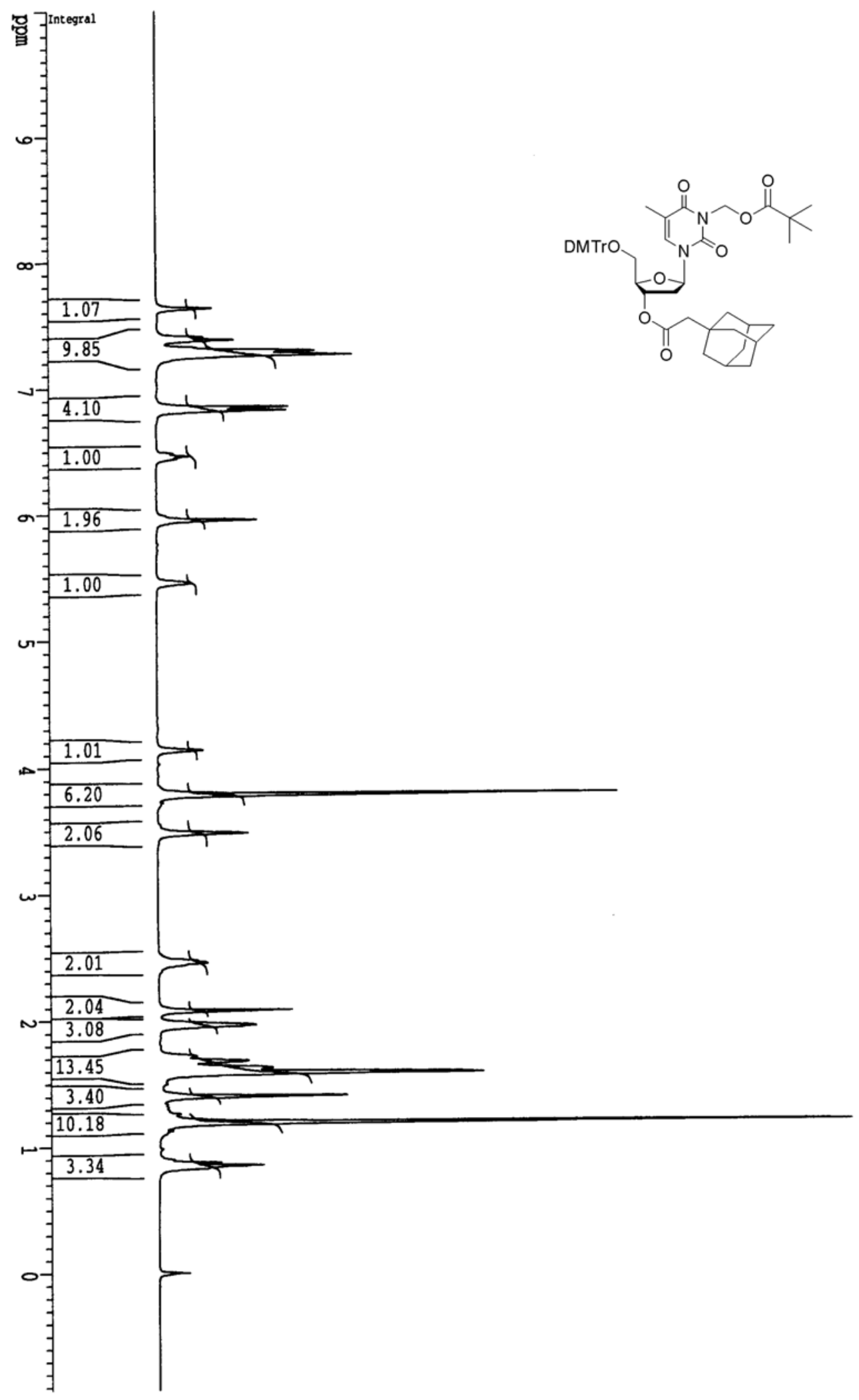




$$
1
$$



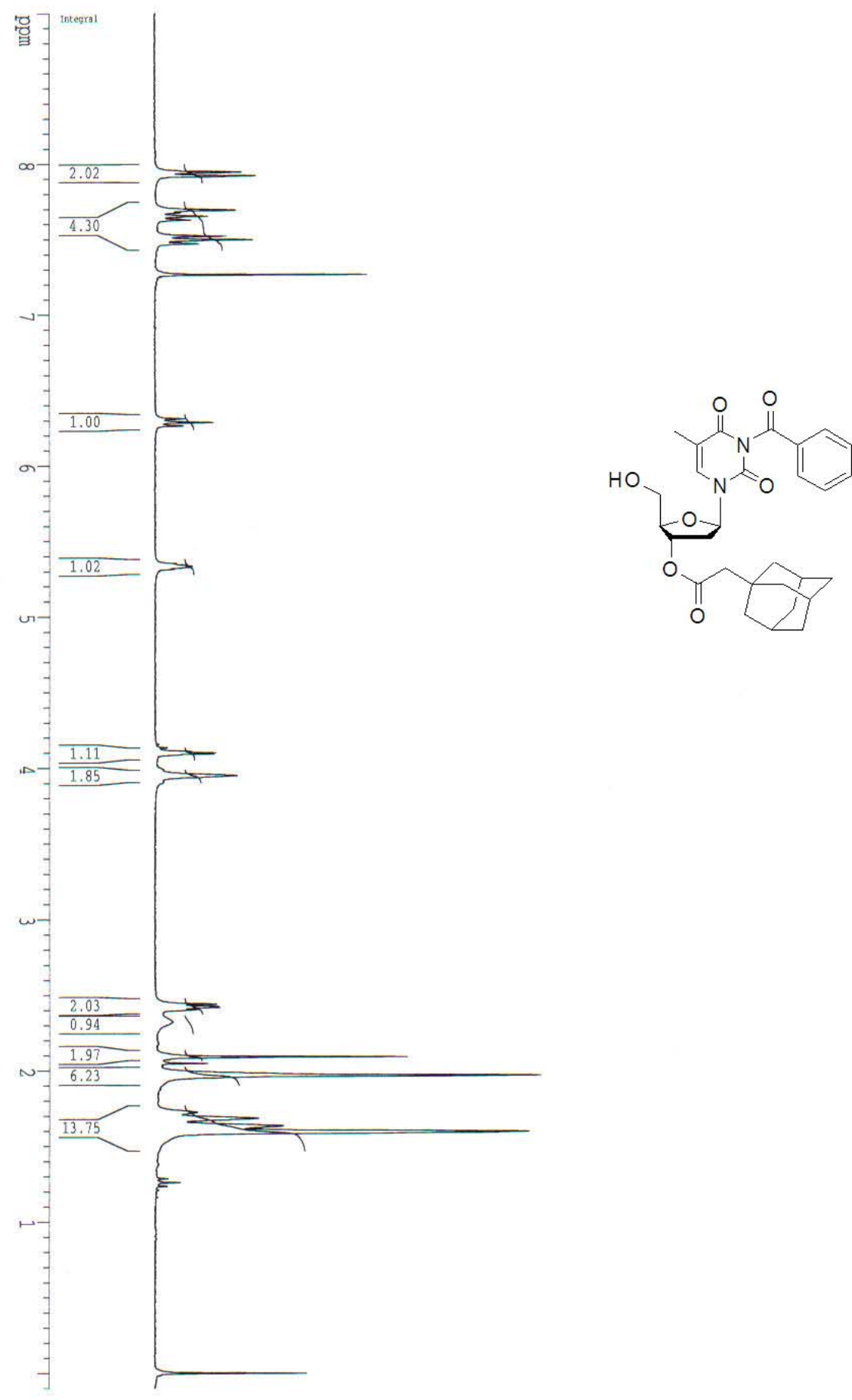


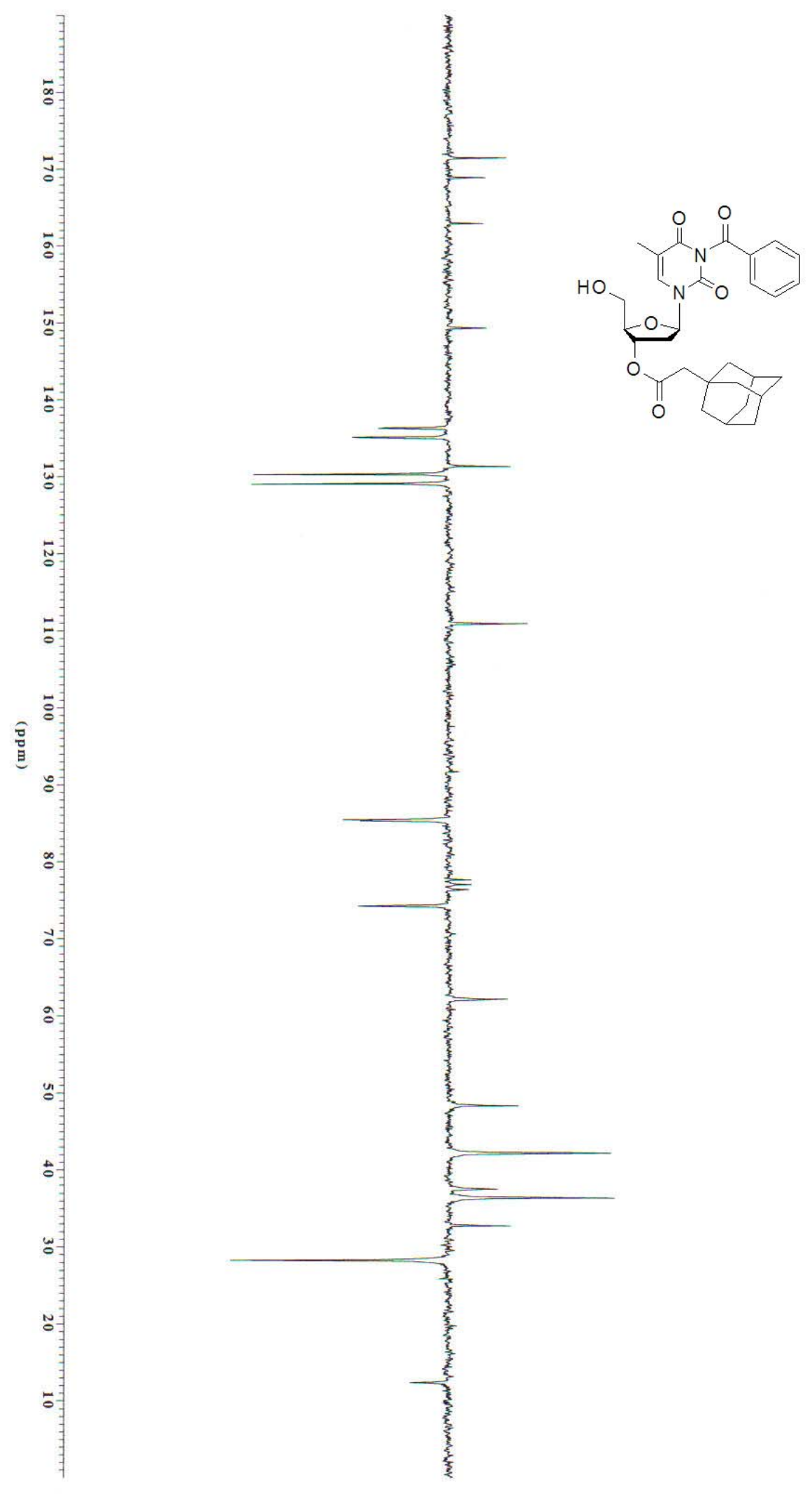




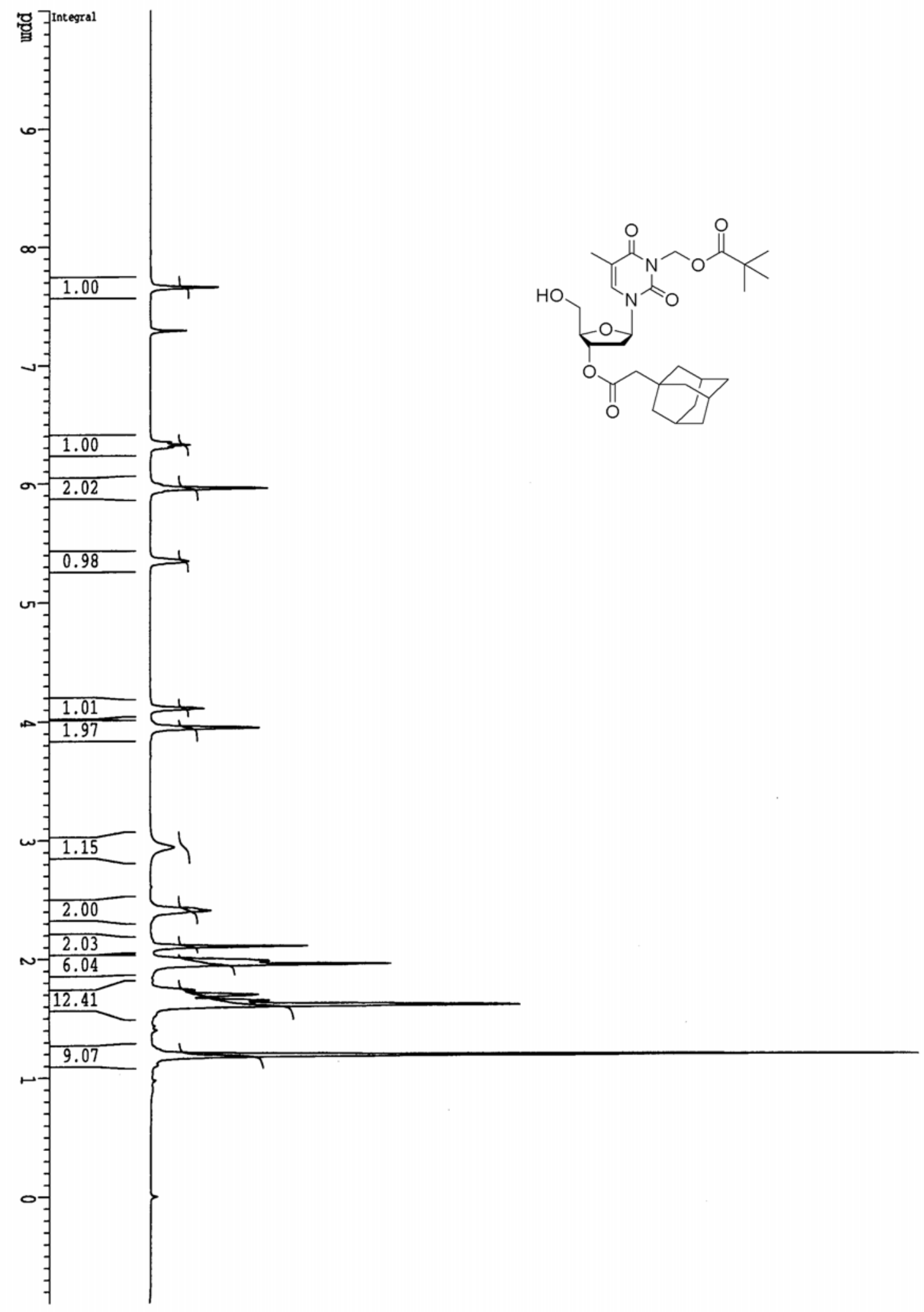




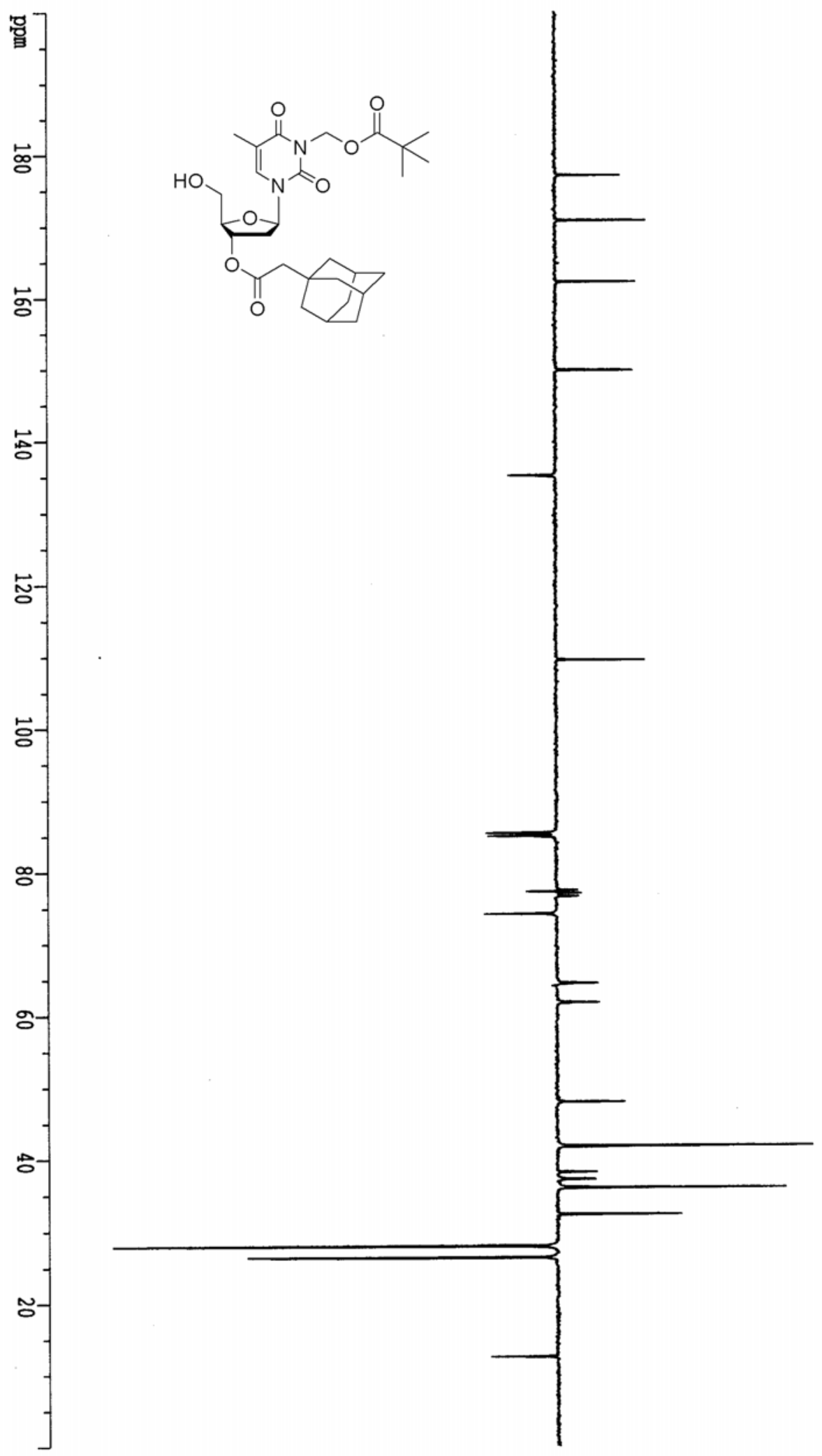




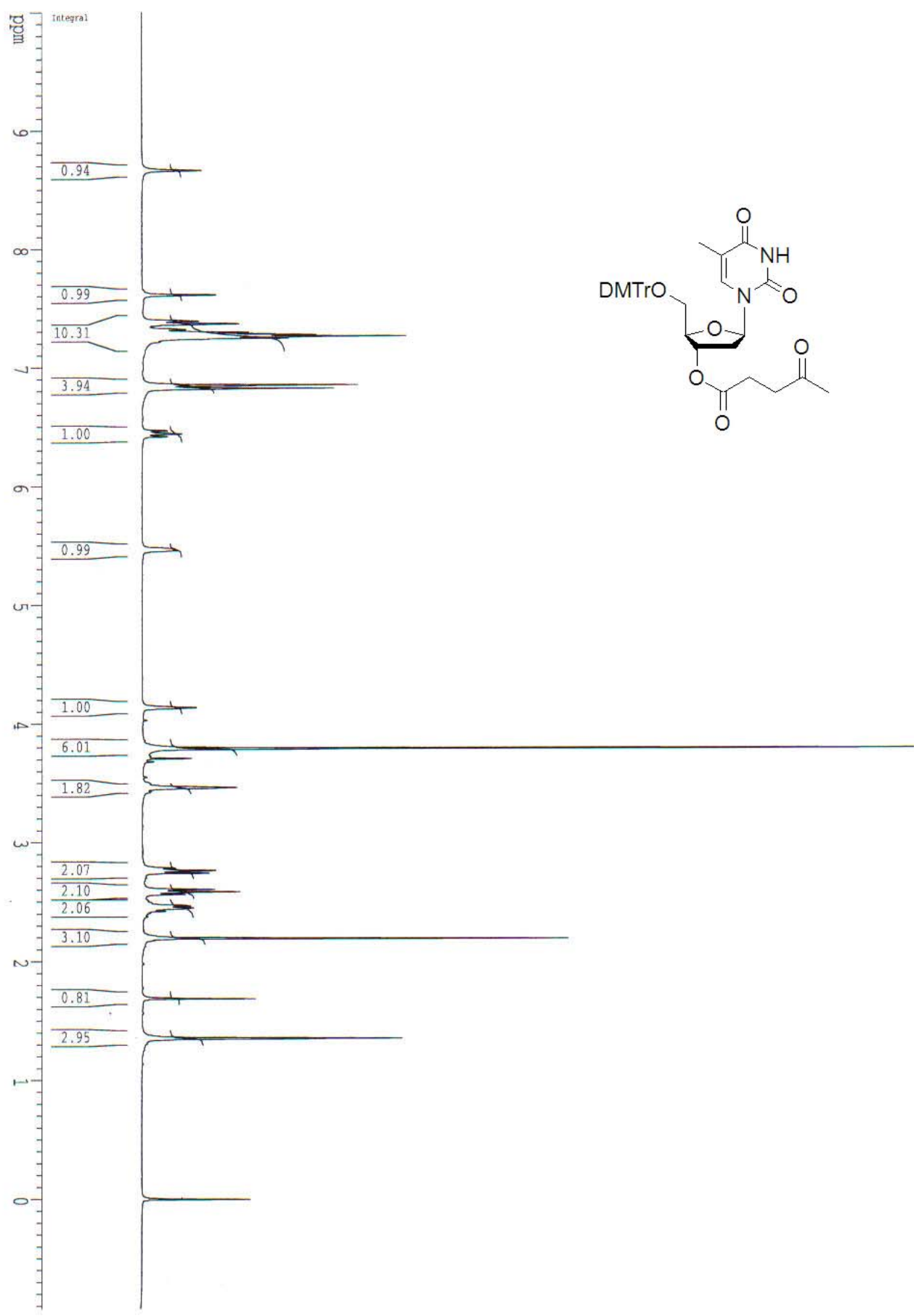



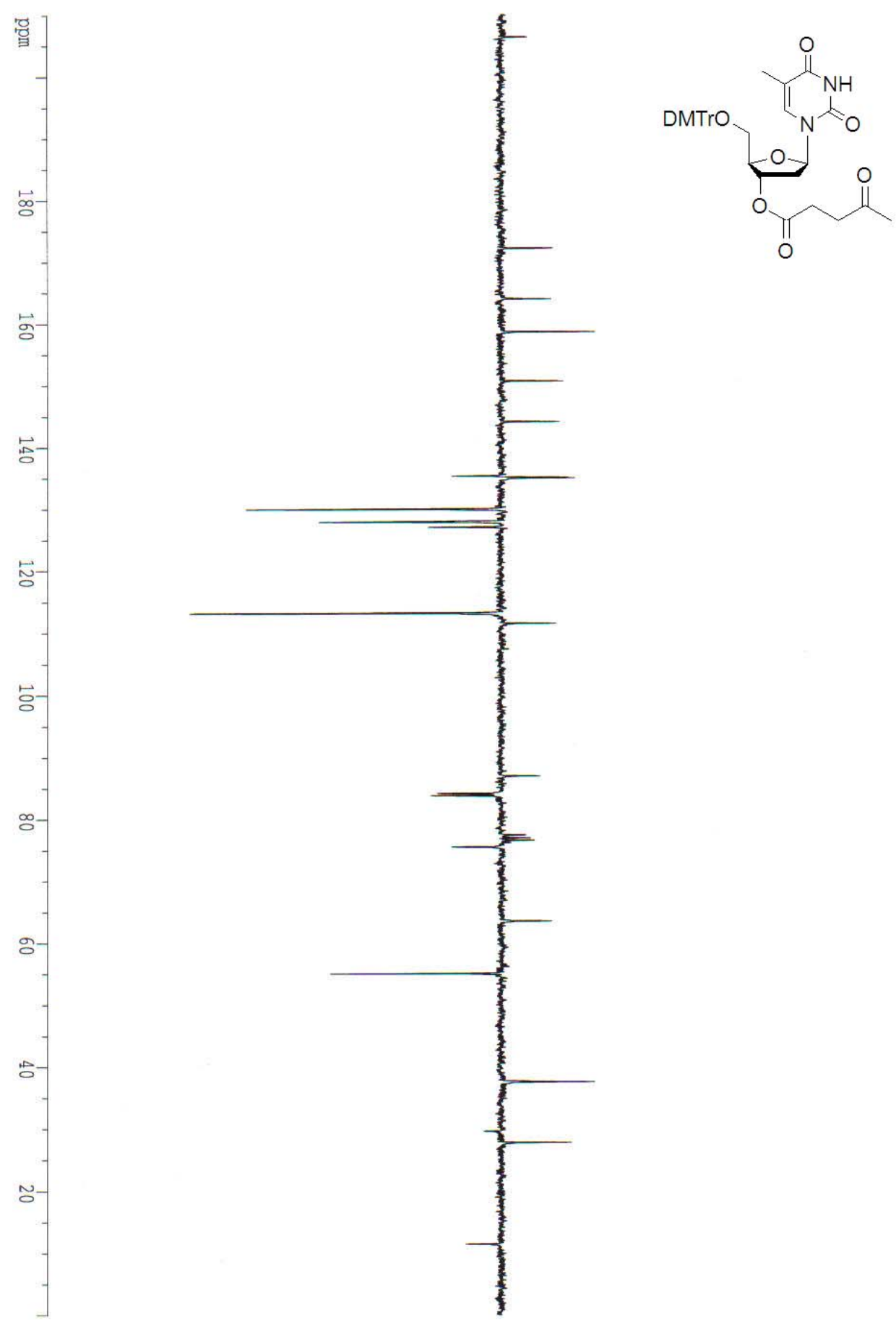


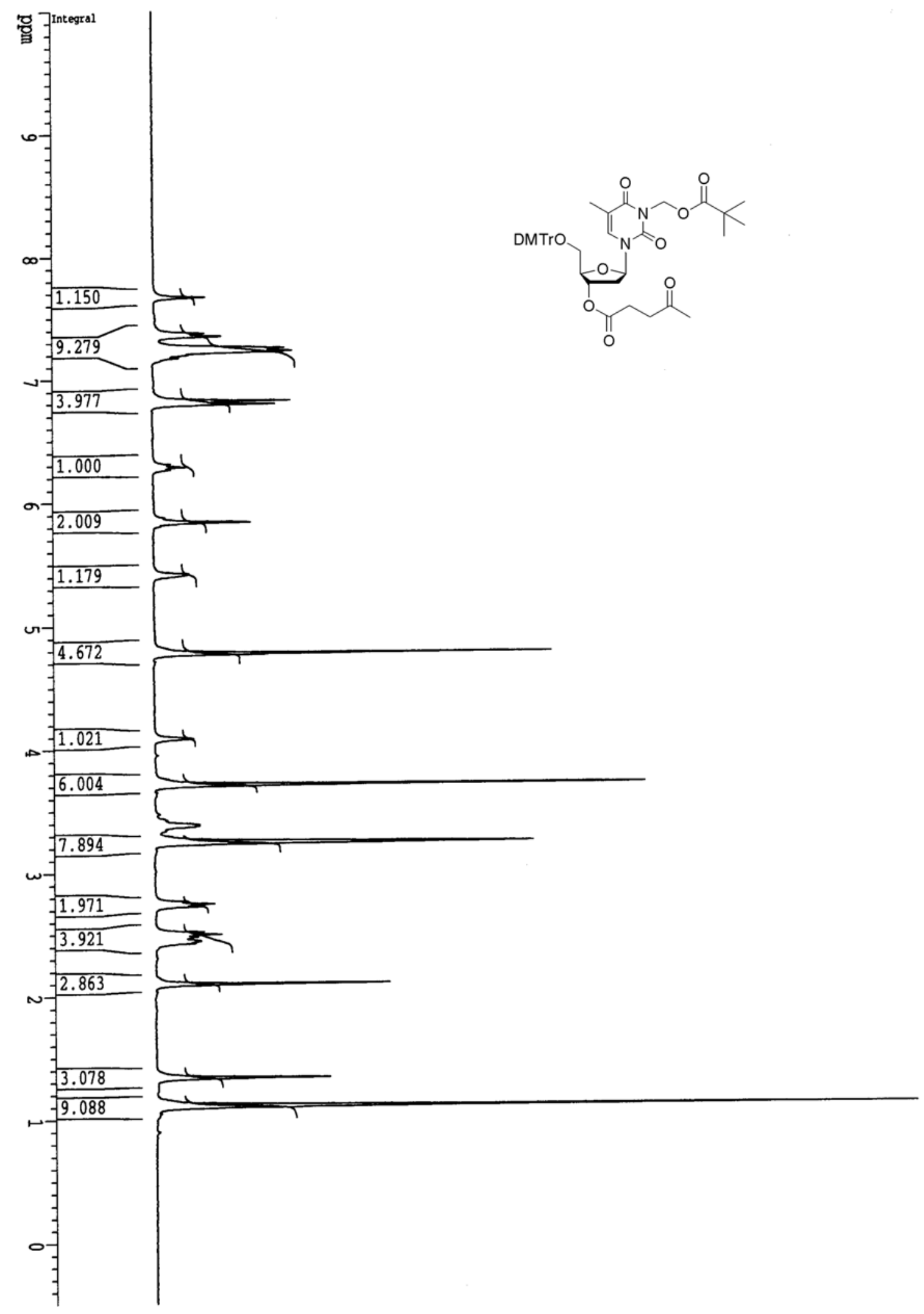




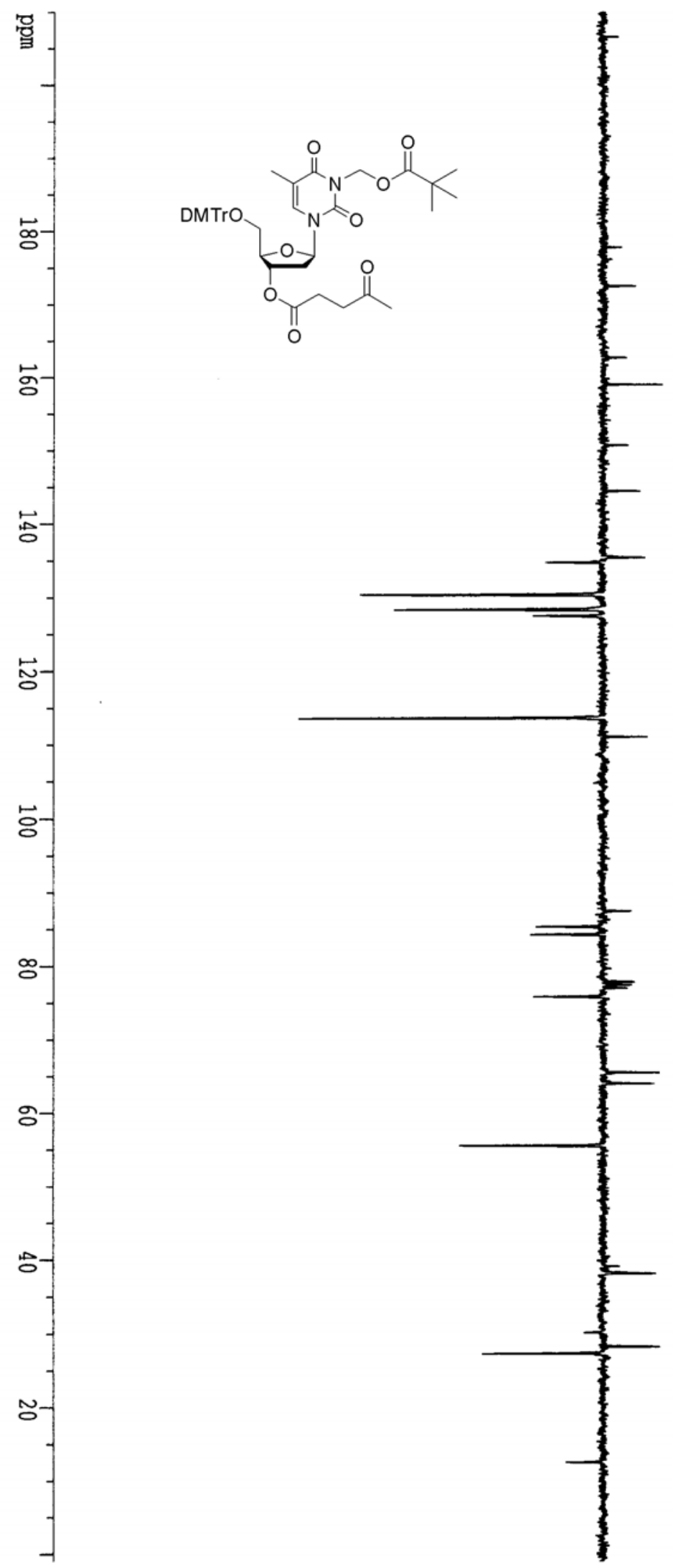




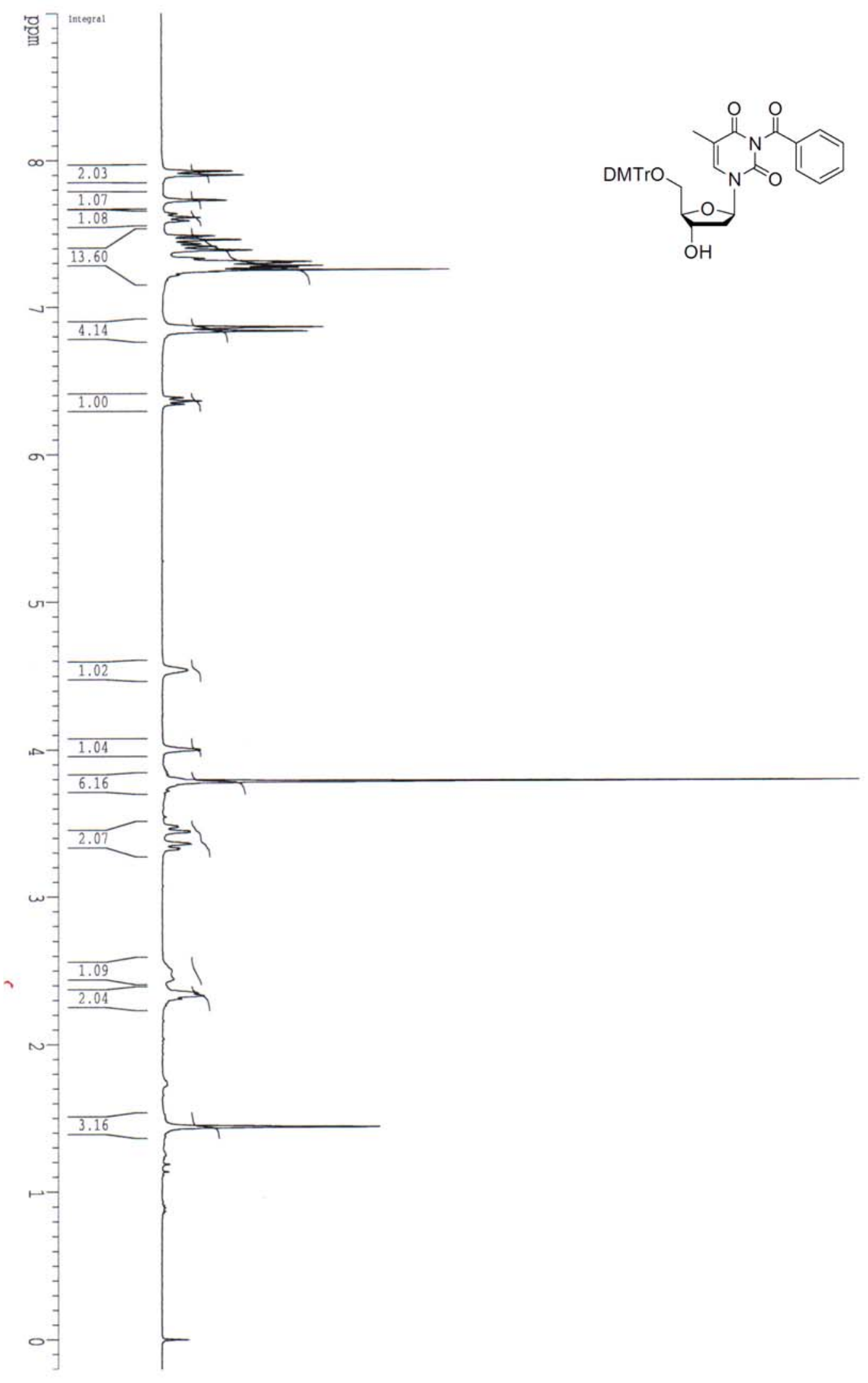




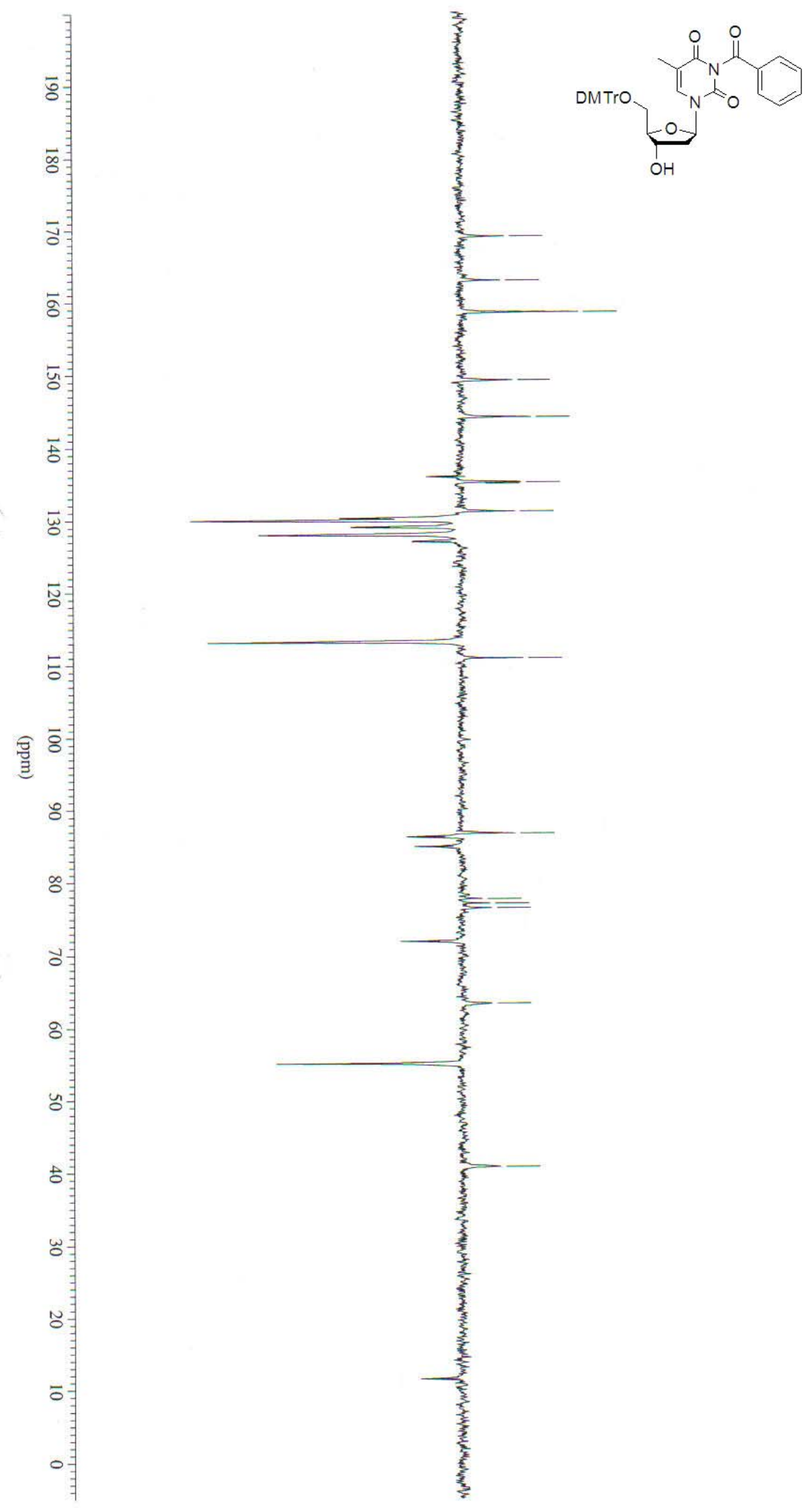




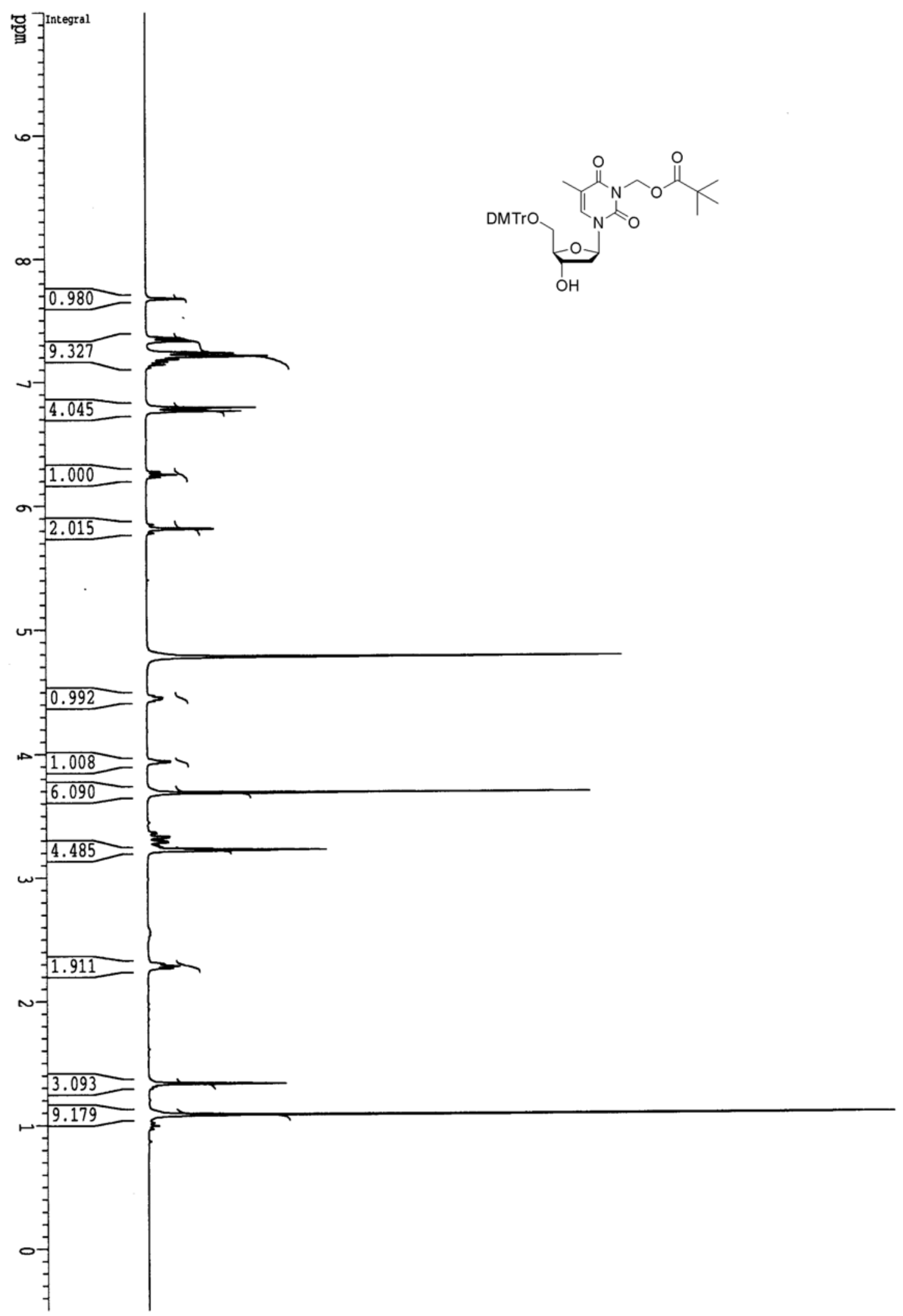




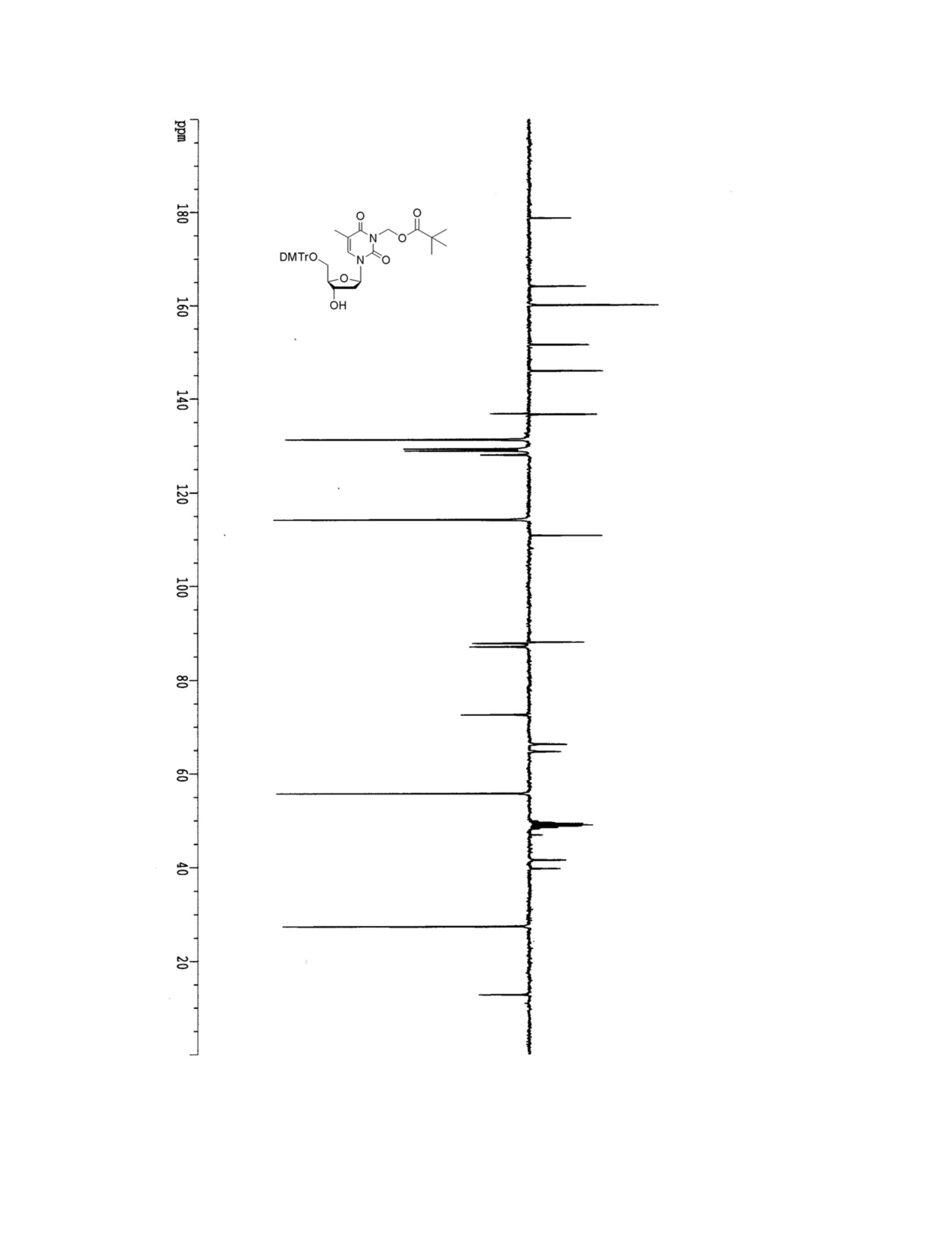




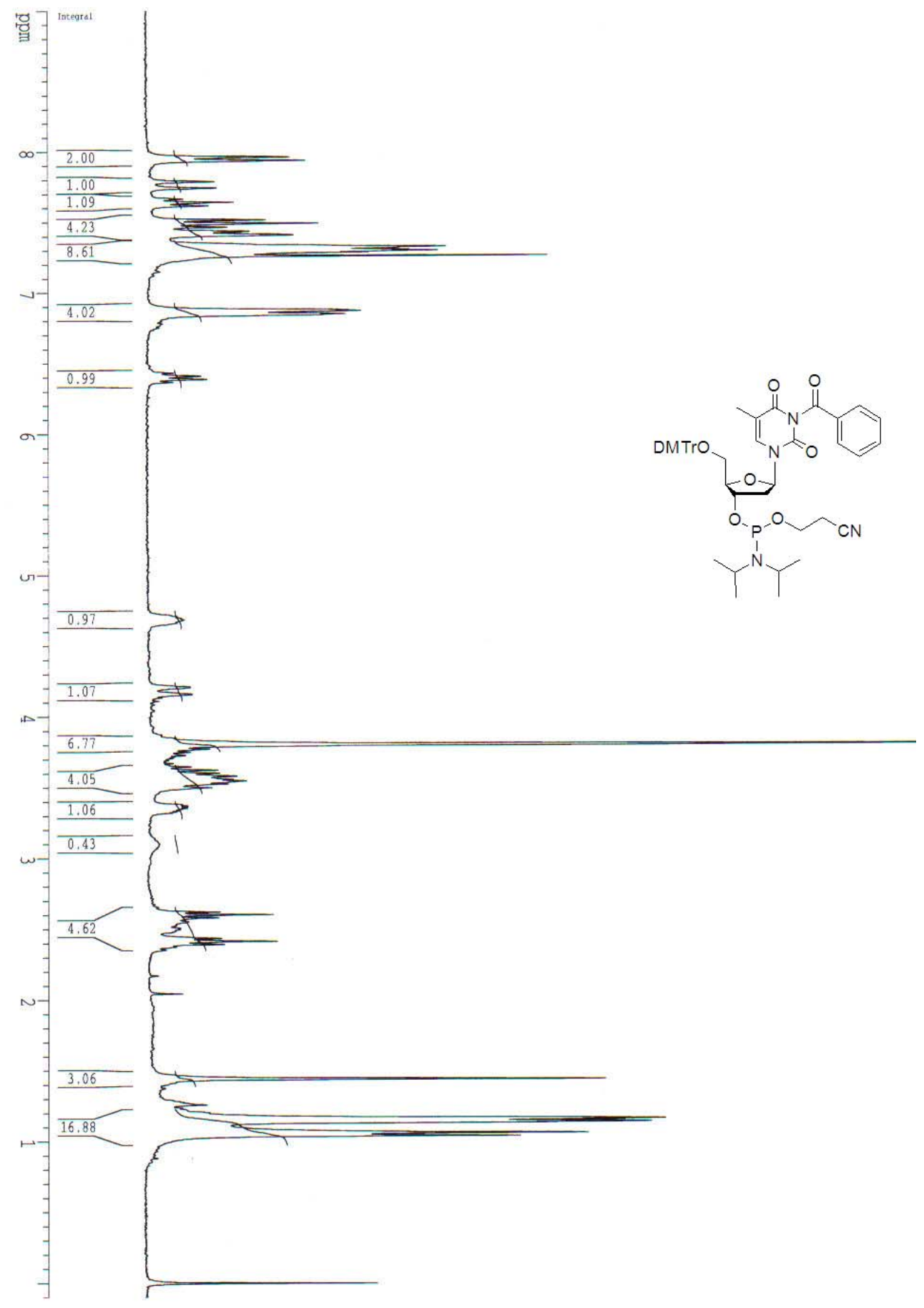




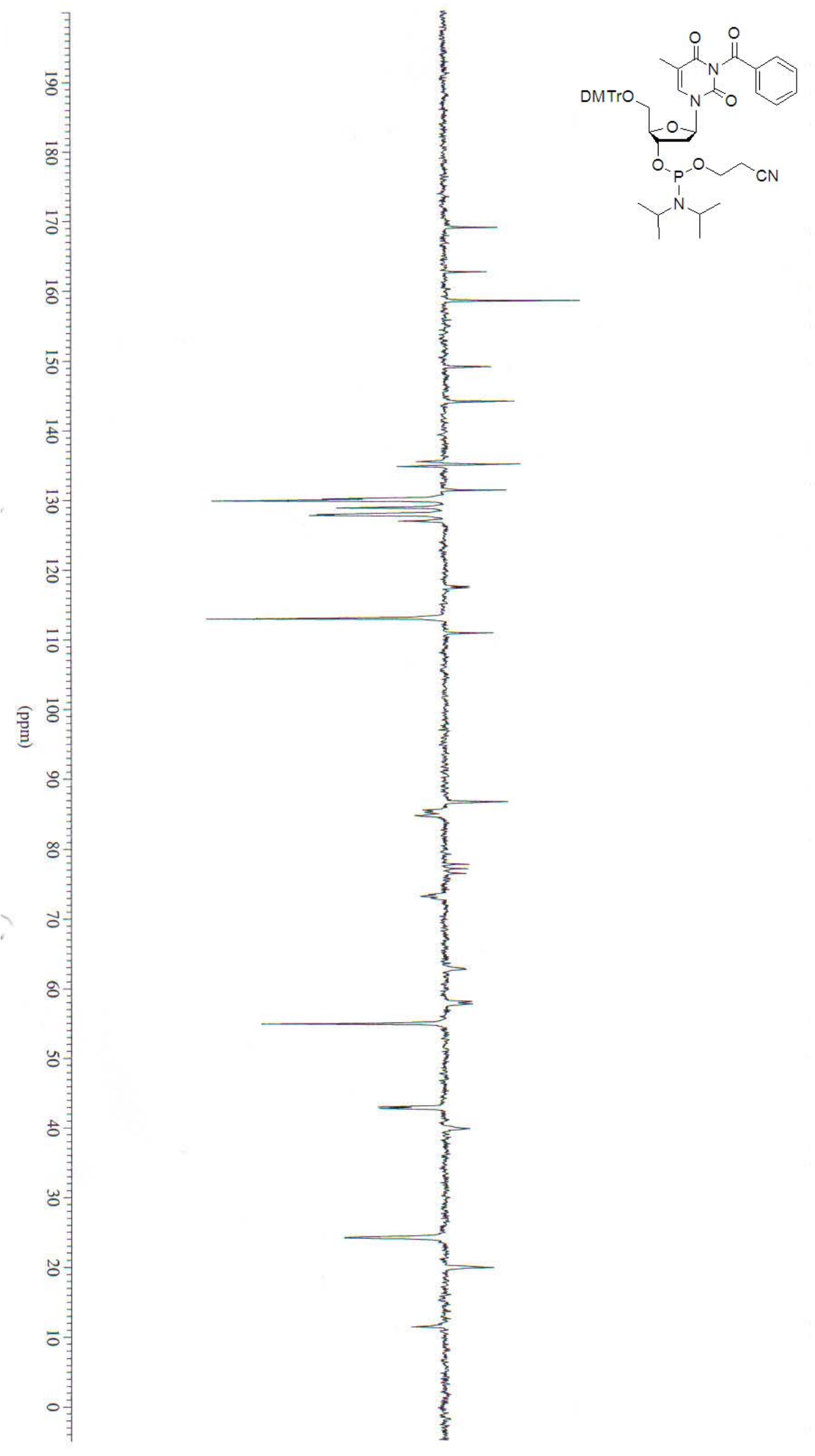




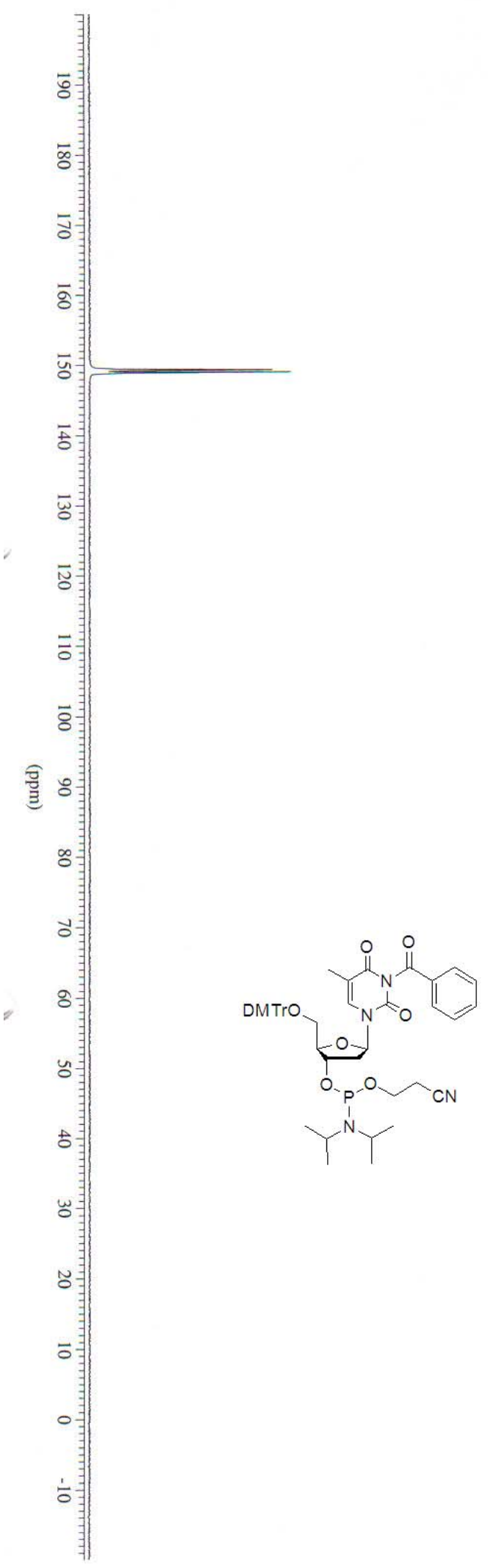




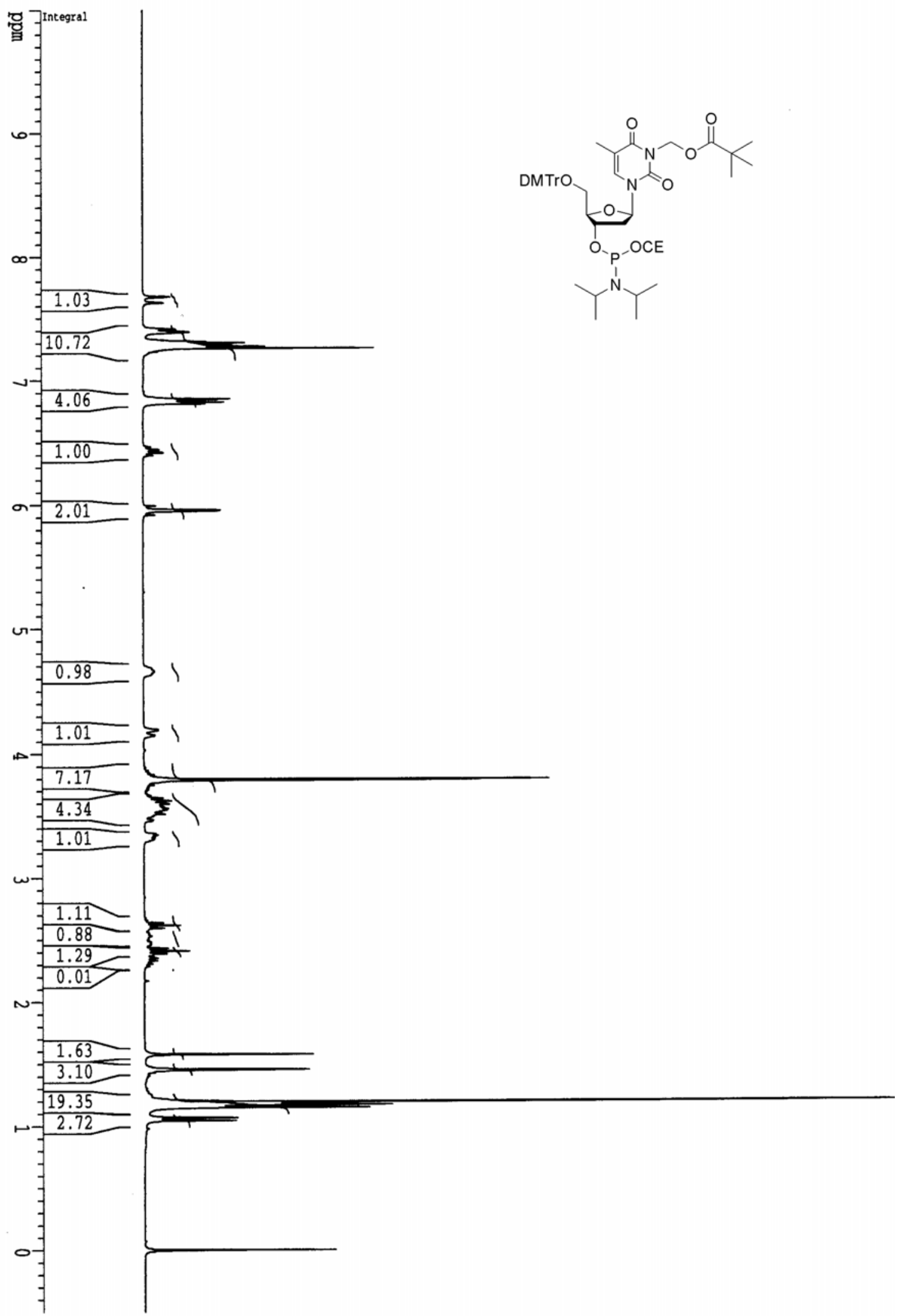




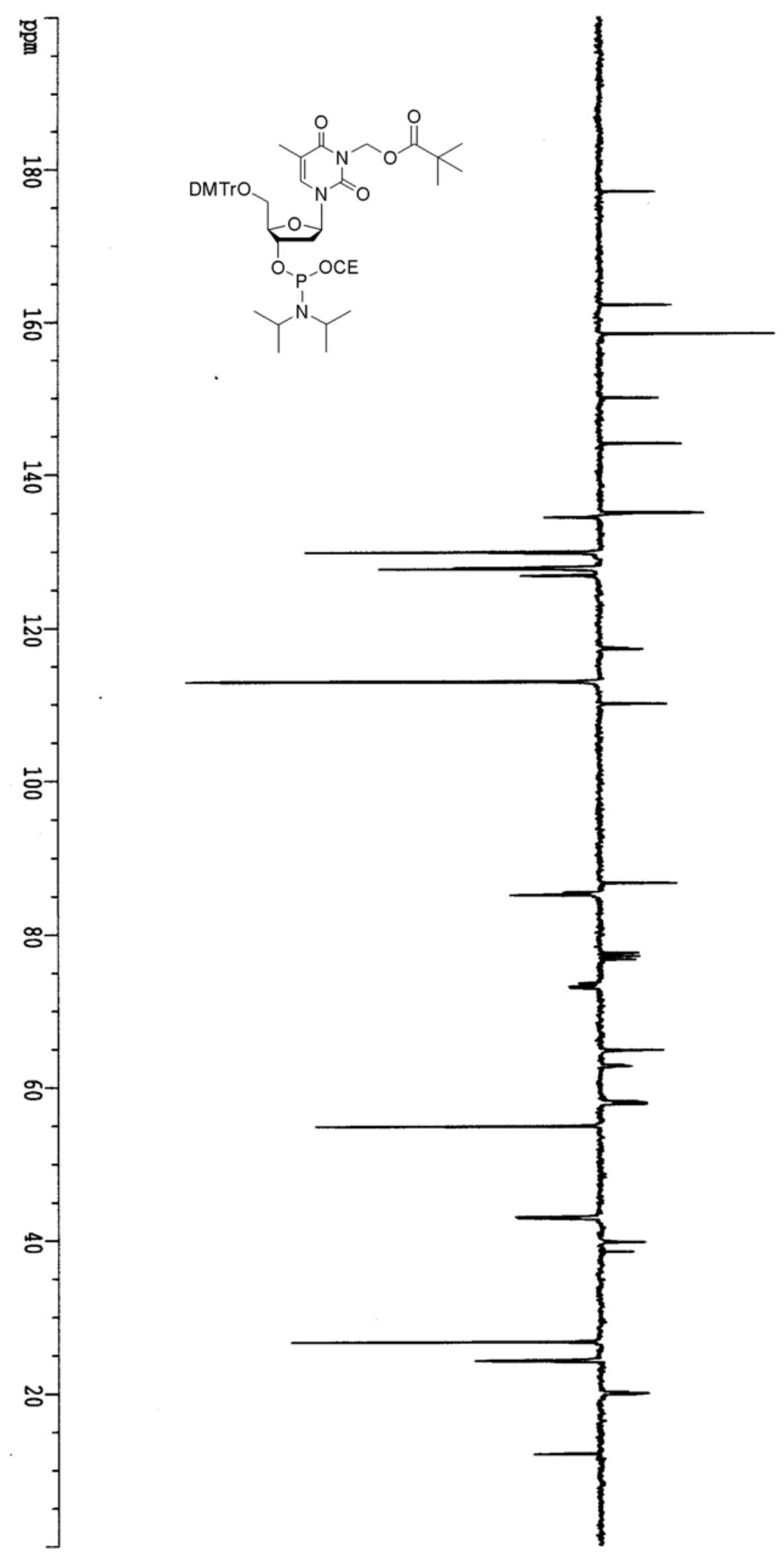




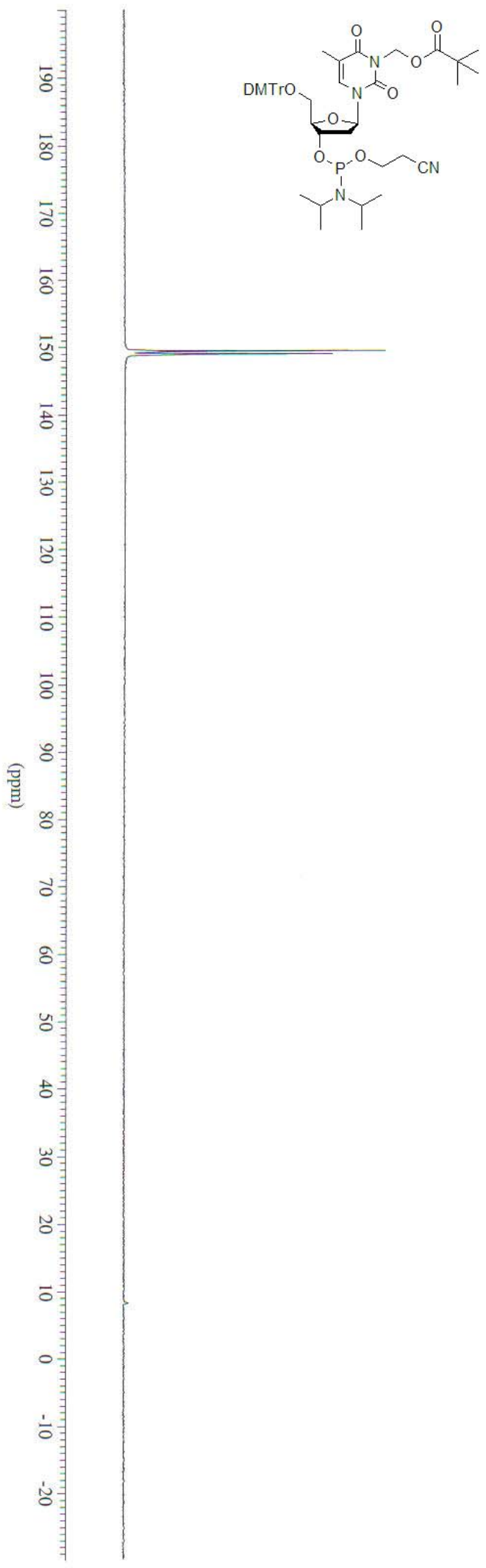



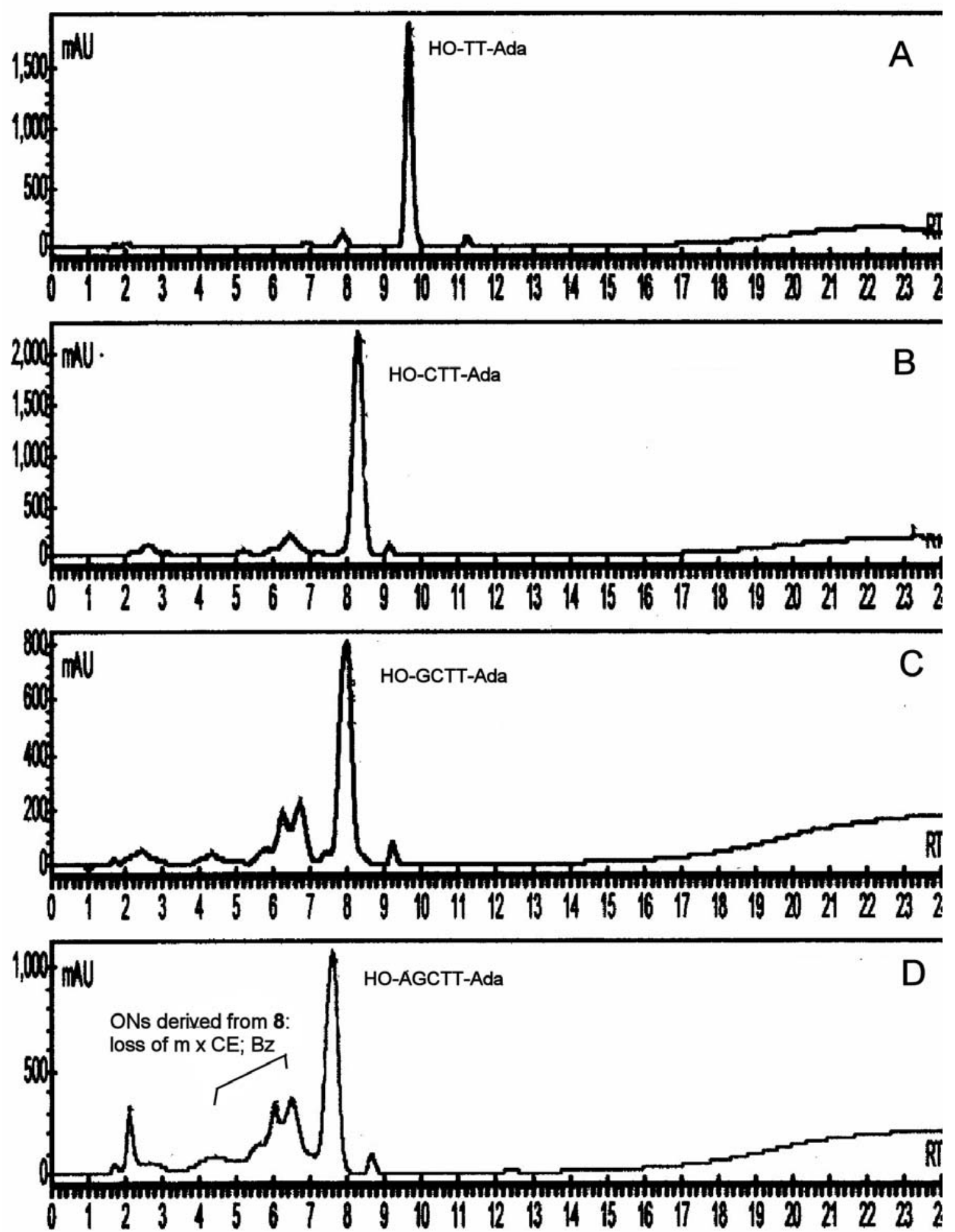

HPLC traces of the growing oligonucleotide chain in the synthesis of pentamer $\mathbf{8}$ after each cycle. $\quad$ A: $\quad{ }^{\mathrm{HO}} \mathrm{dT}^{\mathrm{Bz}} \mathrm{dT}^{\mathrm{Bz}}{ }_{\mathrm{Ada}} ; \quad \mathrm{B}: \quad{ }^{\mathrm{HO}} \mathrm{dC}^{\mathrm{Bz}} \mathrm{dT}^{\mathrm{Bz}} \mathrm{dT}^{\mathrm{Bz}}{ }_{\mathrm{Ada}} ; \quad \mathrm{C}:{ }^{\mathrm{HO}} \mathrm{dG}^{\mathrm{iBu}} \mathrm{dC}^{\mathrm{Bz}} \mathrm{dT}^{\mathrm{Bz}} \mathrm{dT}^{\mathrm{Bz}}{ }_{\mathrm{Ada}} ; \quad \mathrm{D}$ : ${ }^{\mathrm{HO}} \mathrm{dA}^{\mathrm{Bz}} \mathrm{dG}^{\mathrm{iBu}} \mathrm{dC}^{\mathrm{Bz}} \mathrm{dT}^{\mathrm{Bz}} \mathrm{dT}^{\mathrm{Bz}}$ Ada. 

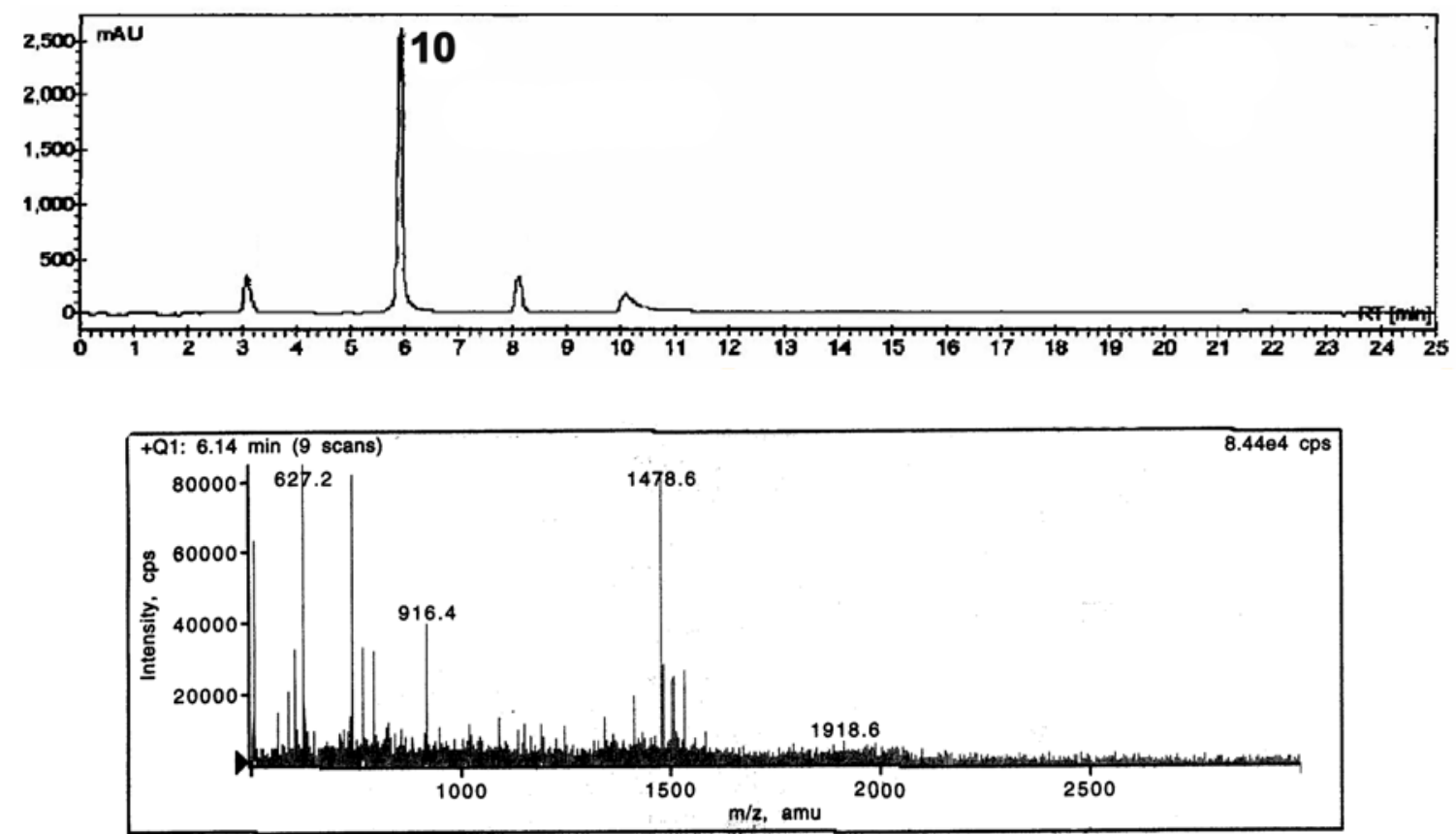

LC/MS chromatograms (254 nm, 0-40\% B) of crude, deblocked pentamer oligonucleotide 10 (5'-AGCTT - 3')

Calculated mass for 10: $[\mathrm{M}+\mathrm{H}]^{+}: 1478.3$ 

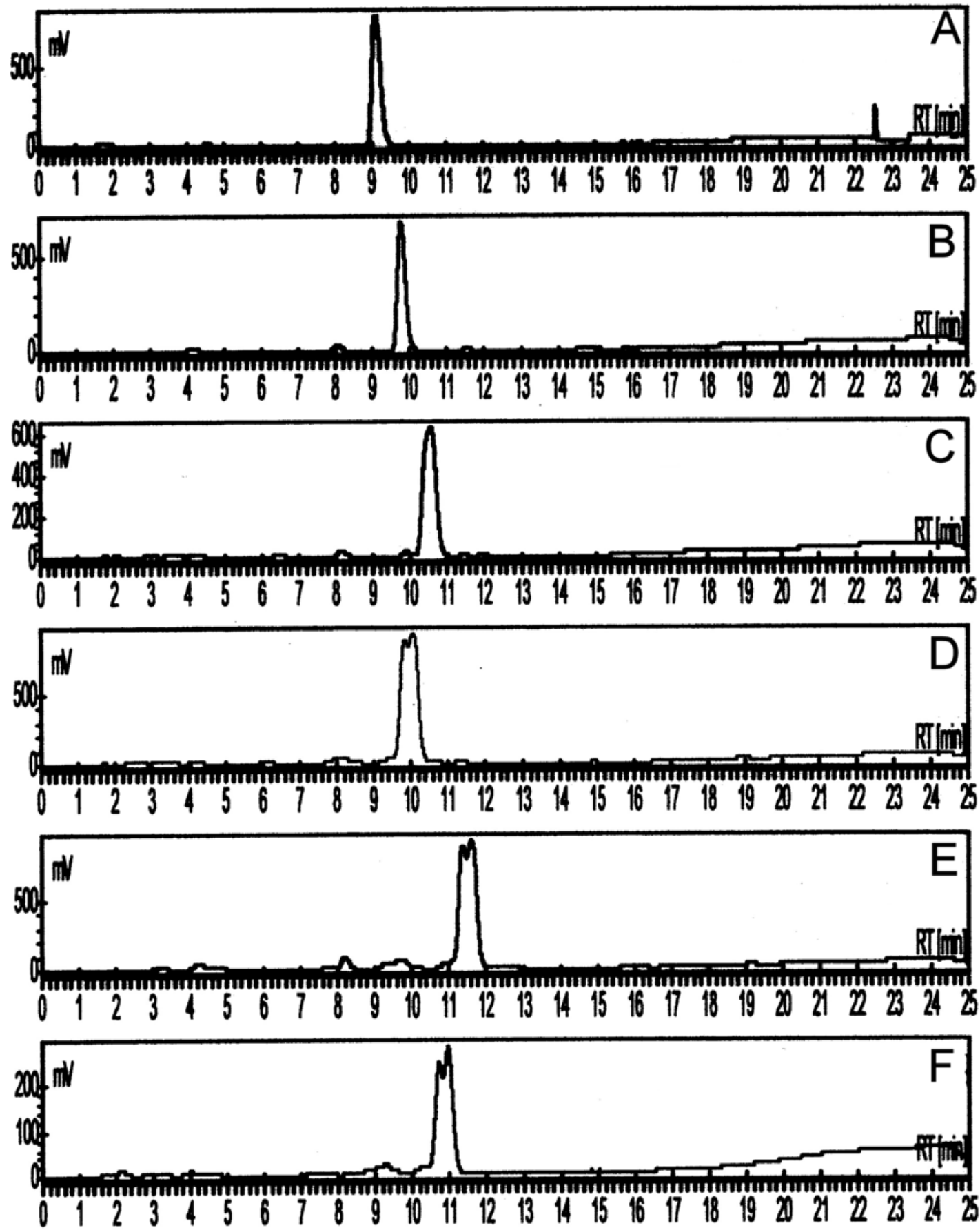

HPLC traces of the growing oligonucleotide chain after each cycle in the synthesis of hexamer

9. A: Starting compound 17; $\mathrm{B}:{ }^{\mathrm{HO}} \mathrm{dT}^{\mathrm{Pom}} \mathrm{dT}^{\mathrm{Pom}}{ }_{\text {Ada }} \mathrm{C}$ : ${ }^{\mathrm{HO}} \mathrm{dC}^{\mathrm{Bz}} \mathrm{dT}^{\mathrm{Pom}} \mathrm{dT}^{\text {Pom }}{ }_{\text {Ada }}$ D: ${ }^{\mathrm{HO}} \mathrm{dG}^{\mathrm{iBu}} \mathrm{dC}^{\mathrm{Bz}} \mathrm{dT}^{\mathrm{Pom}} \mathrm{dT}^{\text {Pom }}{ }_{\text {Ada; }} \quad \mathrm{E}: \quad{ }_{\mathrm{HO}} \mathrm{dT}^{\mathrm{Pom}} \mathrm{dG}^{\mathrm{iBu}} \mathrm{dC}^{\mathrm{Bz}} \mathrm{dT}^{\text {Pom }} \mathrm{dT}^{\text {Pom }}{ }_{\text {Ada }}$; ${ }^{\mathrm{HO}} \mathrm{dA}^{\mathrm{Bz}} \mathrm{dT}^{\mathrm{Pom}} \mathrm{dG}^{\mathrm{iBu}} \mathrm{dC}^{\mathrm{Bz}} \mathrm{dT}^{\mathrm{Pom}} \mathrm{dT}^{\mathrm{Pom}}{ }_{\text {Ada }}$ 

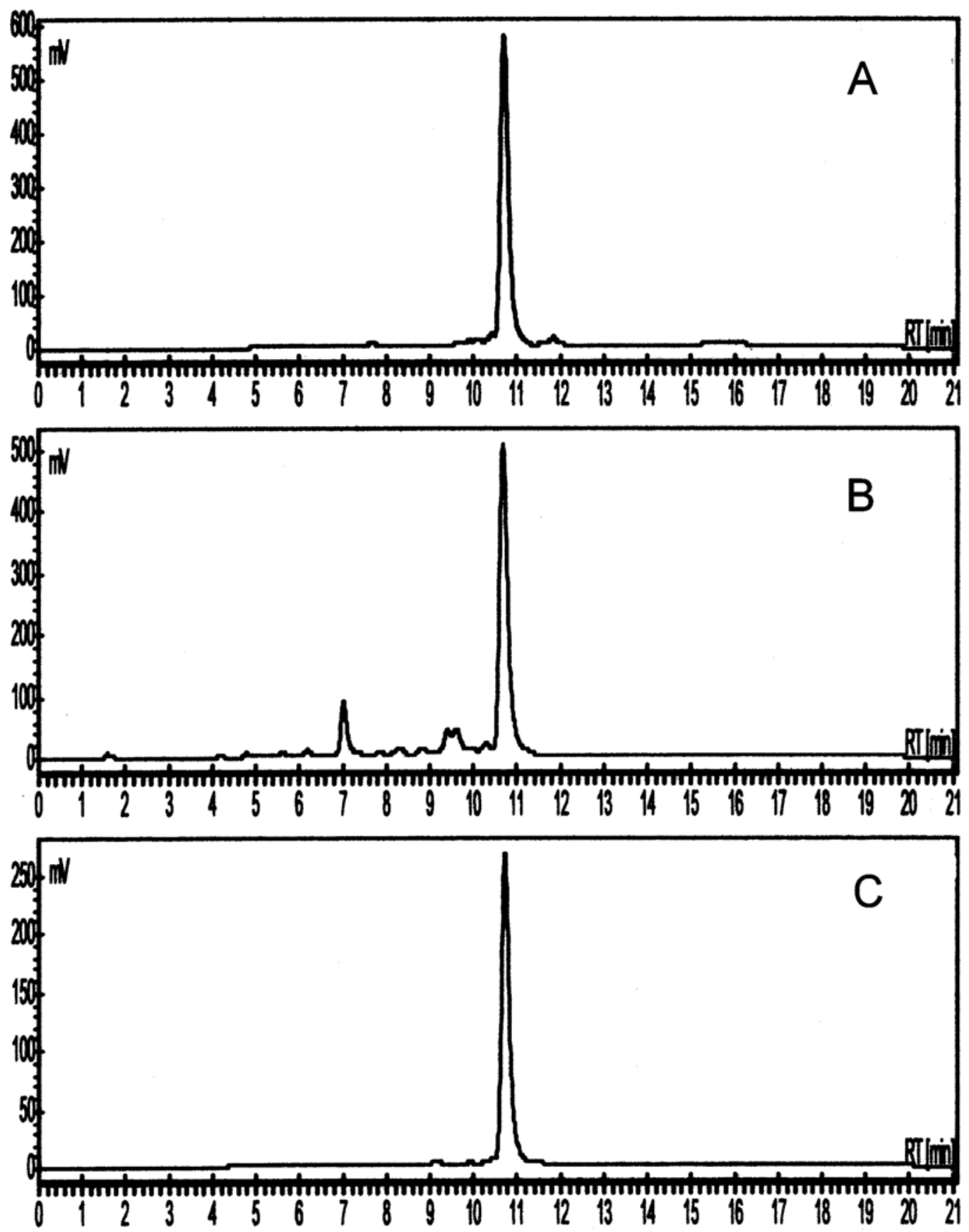

Mono-Q ion exchange chromography traces of hexamer oligonucleotide $\mathbf{1 1 .}$
A: Crude sample after deblocking of $\mathbf{9}$
B: Crude reference sample prepared by standard solid phase synthesis procedures
C: Oligonucleotide $\mathbf{1 1}$ after purification and desalting. 